\title{
Michel Le Guern, Nicolas Beauzée, grammairien philosophe
}

\section{Pierluigi Ligas}

\section{(2) OpenEdition \\ 1 Journals}

\section{Édition électronique}

URL : http://journals.openedition.org/studifrancesi/6663

DOI : 10.4000/studifrancesi.6663

ISSN : 2421-5856

Éditeur

Rosenberg \& Sellier

\section{Édition imprimée}

Date de publication : 1 septembre 2010

Pagination : $375-376$

ISSN : 0039-2944

\section{Référence électronique}

Pierluigi Ligas, « Michel Le Guern, Nicolas Beauzée, grammairien philosophe », Studi Francesi [En ligne], 161 (LIV | II) | 2010, mis en ligne le 30 novembre 2015, consulté le 08 janvier 2021. URL : http:// journals.openedition.org/studifrancesi/6663; DOI : https://doi.org/10.4000/studifrancesi.6663

Ce document a été généré automatiquement le 8 janvier 2021.

\section{(c) (i) (9)}

Studi Francesi è distribuita con Licenza Creative Commons Attribuzione - Non commerciale - Non opere derivate 4.0 Internazionale. 


\title{
Michel Le Guern, Nicolas Beauzée, grammairien philosophe
}

\author{
Pierluigi Ligas
}

\section{RÉFÉRENCE}

MICHEL LE GUERN, Nicolas Beauzée, grammairien philosophe, Paris, Champion, 2009 («Les Dixhuitièmes siècles», 131), pp. 200.

1 Après avoir esquissé une courte biographie et rappelé les principes généraux qui ont guidé Nicolas Beauzée dans l'accomplissement de son œuvre, Michel Le Guern suit l'évolution de la pensée de ce "grammairien philosophe» depuis les articles rédigés pour l'Encyclopédie jusqu'aux trois volumes de l'Encyclopédie méthodique, en passant bien entendu par cet ouvrage savant et consciencieux, mais d'une métaphysique obscure, qu'est la Grammaire générale, ou Exposition raisonnée des éléments nécessaires du langage, pour servir de fondement à l'étude de toutes les langues, publiée en 1767, ouvrage essentiel de celui en qui les spécialistes ont tendance à voir avant tout un continuateur de Du Marsais. Les commentaires savants de Michel Le Guern ponctuent ici les étapes d'une progression où la sémantique, la syntaxe et la rhétorique alternent avec les innovations terminologiques et les préoccupations pédagogiques.

2 Se plaçant dans la lignée de Port-Royal, Beauzée considère que la pensée est une activité cognitive indépendante de la langue, tout en admettant que la langue est l'un des modes d'expression favoris de la pensée. "L'art grammatical est postérieur aux langues - affirme-t-il - et relève de la culture et non pas de la nature». Dans cette perspective, l'objet de la grammaire est l'étude des modalités qui permettent «l'énonciation de la pensée par le secours de la parole prononcée ou écrite».

3 Les théories linguistiques de Beauzée n'échappent pas aux systèmes philosophiques du Siècle des lumières qui, au contraire, les sous-tendent. Sans doute est-ce aussi pour cette raison que chez Beauzée on trouve la synthèse la plus achevée et la somme la plus complète des acquis des diverses grammaires générales de son temps, qui ont pour 
objet la détermination de principes immuables (valables pour toutes les langues du monde, de tout temps et en tout lieu) alors que la grammaire particulière, elle, s'appuie sur des conventions qui changent d'une langue à l'autre.

4 L'étude de Michel Le Guern s'achève sur une annexe où il est question des lectures grammaticales et rhétoriques de Beauzée, suivie des œuvres du grammairien, d'une liste de travaux récents et d'un très utile index des noms. De l'aveu de l'auteur, cet essai n'est pas une étude complète des réflexions de Beauzée sur le langage. Toujours est-il que l'ampleur de la recherche, la nouveauté des points de vue et l'importance de la documentation réunie font de cette évocation une illustration de la pensée linguistique du XVIII en général, et servent à montrer, par la mise en évidence de l'originalité d'un logicien vigoureux qui a fait avancer la science grammaticale en donnant sur les questions importantes des vues meilleures et plus saines que ses prédécesseurs, la complexité des débats qui traversent cette période de l'histoire des idées. 